\title{
Effectiveness of Roleplay in Enhancing Speaking Skills of Tertiary Level Learners
}

\author{
M.Shyamala Bharathy \\ English Department,SSN College of Engineerng,INDIA
}

\begin{abstract}
The changeover from the existing methodology of talk and chalk approach for language acquisition to technology driven approaches in the educational setup is recommended for improving language skills especially speaking skills. Though technical skills are important, a diagnostic test is conducted on speaking in English for the purpose of placement. Recruiters require candidates to possess excellent communication skills to adapt to international scenario. Therefore communication skills laboratory was introduced to enable task based language learning thereby equipping the student with the required speaking skills. This paper discusses the importance of speaking skills for the technical student and brings forth an analytical perception of how role play emerges as a successful task based learning for all the four skills.
\end{abstract}

\section{Significance Of Introducing Technical English}

Technical English for engineers was introduced by Anna university for the undergraduate learners of $\mathrm{BE} / \mathrm{B}$.Tech degree programme in the first year of the study and tested in first and second end-semester examination. The purpose of introducing the course was to improve their communicative competence in the workplace. The focus of the course design was to equip the students in all the four language skills (LSRW) to meet the professional demands and also to inculcate interpersonal communication skills in English. But over the years, though the syllabus had all the four language skills, the testing was and is done only on reading and writing. Students are equipped in the knowledge of grammar, writing letters, giving instructions, suggesting recommendations etc...Due to the mushrooming of the IT and ITes sector in India, there was a pressing need to equip the student in the spoken language.

\section{Communication Skills Laboratory}

Therefore, in 2006, Anna university, made communication skills mandatory in the third year of study. The Communication skills laboratory had to be equipped with systems with the required configuration, Hi-class software, LCD projectors, mike, video camera and a TV. The lab was divided as English lab and Career lab wherein the English lab has the lab sessions and the career lab has sessions on presentations and group discussions. Testing is done in the end of the semester with the English lab component comprising of reading, listening and common errors in English. Speaking skills are tested in the Career lab. The syllabus copy is annexed for reference.

In the language laboratory, using software like Globarena and TOEFL mastery, reading, listening exercises, phonetics, intonation, stress pattern are taught. In the career lab, students are trained in presentation, group discussion and interview skills to face the future demands of the prospective employment. The curriculum also comprises certain task-based usage of language to improvise the students oral skills and social skills, and it has also proved successful in real time practices. It encourages primarily appropriate completion of real world tasks rather than on accuracy of prescribed language forms.

\section{Task Based Learning (Tbl)}

Task Based Learning is effective for communication language teaching. It is contrary to the teacher centered approach wherein the student is left with no choices other than an artificial situation, often with drills and already structured dialogues to be practiced .In the Indian scenario TBL is an upcoming new element as it is becoming popular and has garnered considerable change in the teaching methodology . The concept has also influenced syllabus designing, classroom teaching and in the assessment of learners. TBL is practiced in school classrooms as well as in colleges. The most important criteria aiding in TBL is learner-centered and also fun to learn.

Nunan tries to enumerate some of the key factors in his book task based language teaching. He deems that TBL is ideal for selecting content for a need based language as there is emphasis on 'learning to communicate through interaction in the target language' and 'introduction of authentic texts into the learning situation'. TBL offers 'provisions of opportunities for learners' and 'provision of opportunities for learners to focus not only on language but also on the learning process itself'. It acknowledges 'enhancement of the learners 
own personal experiences as important contributing elements to classroom learning' and linking of classroom language learning with language use outside the classroom.(Nunan,2004).

Some of the components of TBL are:

1) Setting goals and objective to develop communicative ability of the learner.

2) Input is rendered by teacher by giving a sketch of how things should be approached and selected for performance.

3) Activation -children get themselves to undergo rehearsals and regressive practice.

4) Teachers take different roles unlike traditional ones and thus act as good guide, counselor, evaluator etc.

5) Learners role differ from his routine self and thus act as a independent learner, material and course designer, self evaluator, peer advisor etc...

6) Settings- creating an infrastructure with all the equipment like hi-class software, LCD projector, and a comfortable ambience of an air-conditioned room where the student can work towards a better goal of achieving efficiency in their language skills. Subsequently in the language laboratory the researcher observed and found that of all activities and TBL like GD, Jam, debate, miming etc, role play emerged as one of the effective task, that could support not only linguistic competence of the language learner but also develop communicative ability of the learners.

\section{Role-Play}

Role play is a teaching strategy that fits within the social family of models(Joyce and Weil, 2000). Thus role play advocates natural method which recommends a process of learner discovery through trial and error. Finally the ultimate goal achievement in acquiring language proficiency and fluency is supported. Here the researcher would like to bring forth Krashen's theory of language acquisition called comprehensible input (i+) where it is expected that the four kills are supportive to combine the existing knowledge in the learner and eventually results in the understanding of the target language.

The benefits of using a role play are innumerable and fruitful. Firstly the reader is exposed to true learning where he is not made a passive observer but an active participant. According to Jones(1982) "students must accept the duties and responsibilities of their roles and functions and do the best they can in the situation in which they find themselves". It helps the learner bring life to the written forms and immediacy to academic material which most of the time lies in the form of theory and is very descriptive. It can encourage student to empathize with the position and feelings of others which is in fact missed in the normal course of a teaching learning environment.

Role-play enhances clarity in understanding, interest to participate and confidence to perform in students. It helps learners to empathize with the role he/she enacts and thus motivates the learner to have a better understanding of real-time problems and the solutions. It helps students practice speaking skills like debating, enacting, reasoning and negotiating .Moreover it also helps them to adapt to unexpected situations in real-life.

The aim of introducing role play to the students was to promote LSRW skills and also to actively involve students in speaking. The class was divided into teams of six. The students were selected randomly for each group. Each group consisted of good, average and below average student. The students were allowed to choose a topic of their own choice from a broader frame work. One such activity the teacher suggested was a letter writing exercise depicting an incident that which takes place in day-to-day life. The letter had to be addressed to the editor of a newspaper either voicing their opinion over the issue or complaining about the issue . The students were allowed to browse through resources like magazines, online news reports, etc... as a pretask activity. The students were asked to come prepared for a discussion and present their views in the next class. In the last class the students enacted the entire issue as a skit thereby enabling participation from all students. Each student had a role to play and based on the preparation and discussion of the social issue, the students actively participated in enacting the role-play. Each team had to present the skit for a duration of 15 minutes. After the skit is enacted, the floor is thrown open to the audience for discussions or queries that arises. The feedback is given immediately both by the teacher and the other students as peer feedback. The final written script of the skit is submitted for analysis.

The activity is extremely gripping and enjoyable as the students have total involvement. The activity adheres and supports the ideology of natural approach wherein a great way to practice conversation skills is to collaborate students to solve a problem or complete an assigned task. There is a meaningful exposure to all the four skills(speaking was primary as it was dominant skill posted at every stage). Krashens language learning acquisition theory believe that combined input of all the four skills of both productive and receptive skills would help them acquire better understanding and promote them with effective communication to target any kind of testing and evaluation in academic as well as real time situation and issues.

These activities enable the students to be part of the reviewing team thereby giving instant peer feedback and opinions that do not affect the morale of the student. As a part of sourcing ideas the students watch 
television, watch video clippings in you-tubes and listen to music $\mathrm{CD}$. Thus the students are given opportunity to be more responsible to make their own decision thereby encouraging self-directed program rather than teacher directed learning by choosing their own content from the available resources. The ultimate step and goal is to enable every learner become responsible for their own learning.

Reading skill is exercised as they read materials relevant to the context(print material, online material). They also read their own scripts before submitting to the teacher (proof-reading), they also read the scripts of other groups(peer assessment). These help the student to be a good critic, assign new roles and give them the opportunity to self-monitor their own performance as well as the others.

Last but not the least they had to write and express their original ideas on the concept area on a specialized form of writing on a literary genre (namely dialogue writing, play writing etc.)and using all the ideas generated they wrote letters to the editor about the issues they had enacted.

The students were allowed to access the net in the language laboratory and the theory underlying this research is Krashens $(c=i+1)$ ideology of bringing the concept of comprehensible input. Thus role-play enables the fact that learning is fun and performance ultimately leads to improved spoken skills.

\section{Drawbacks Of Role-Play}

In spite of identifying a very good feedback observation from students about the positive end of using a role play, we can never deny some factual factors of the disadvantages in involving role play in teaching learning environment.

- Sometimes learners become very self conscious and end up in an embarrassing situation feeling awkward and results in unproductive performance .

- It is practically difficult in a larger classroom of 60 to have role play and assess the role-play.

- Sometimes there are passive listeners and as a result a disinterested group distracts the class and stops paying attention to the environment.

- If more students are involved, the role playing might become a chaotic mess.

- Adequate teachers support and human power is required to bring forth better guidance and support to assist the learners.

- Teachers should be given training programmes to equip themselves with the required skills in facilitating a congealing environment and guidance to move the learners for further progress.

- The concept of learners attorney is sometimes quite shocking and continues to be a surprise for the learners and teachers to accept and probably they end up questioning the legitimacy of the program that differs totally from the conventional methodology.

\section{References}

[1]. Poorman, P. B. (2002), Biography and role-playing: fostering empathy in abnormal psychology. Teaching of Psychology, 29(1), 3236.

[2]. Jones, K. (1982). Simulations in language teaching. Cambridge: Cambridge University Press.

[3]. Teahan, J. E. (1975). Role playing and group experiences to facilitate attitude and value changes. Journal of Social Issues, 31 (1), $35-45$.

[4]. Joyce, B. \& Weil, M. (Eds.). (2000). Models of teaching. Boston. Allyn and Bacon.

[5]. Teahan, J. E. (1975). Role playing and group experiences to facilitate attitude and value changes. Journal of Social Issues, 31(1), 35-45.

[6]. Lori Jarvis. et al,2002, Role-Playing as a Teaching Strategy, CPU McGregor, J. (1993). Effectiveness of role-playing and anti-racist teaching in reducing student prejudice. Journal of Educational Research, 86(4), 215-226.

[7]. Nunan, David. 2004, Task-based language teaching, CUP Krashen, Stephen D. Principles and Practice in second Language Acquisition. Prentice-Hall International,1987.

[8]. Krashen, Stephen D. Second Language Acquisition and Second Language Learning.

[9]. Prentice-Hall International,1988.

[10]. Gardner and Miller .1999,Establishing self access: Theory to practice, CUP. 